Wrow back its blood with sufficient force to create a bruit? We have not met with such a case, though theoretically io is of conrse possible.

In conclusion, let us point out that in quiet states of the eirculation in health and in anæmia the continuous venous hum shows augmentations, systolic and diastolic, produced by accelerations of the onflowing blood; that at times the brait may be actually discontinuous with systolic and diasvolic phases, which again represent accelerations in the onflowing blood. Note, as characteristic of this, as we may ferm it, normal circnlation that the systolic augmentation corresponds with the collapse, the emptying of the vein; that in pathological states marked by a full right side of the heart and distended veins a systolic venous bruit may be heard due to a wave of back.flow. Note, as characteristic of this abnormal sbate, that this bruit corresponds with the systolic pulsation, the filling out of the vein.

\section{ON A METHOD BETTER THAN SUSPENSION OF APPLYING A PLASTER JACKET.}

BY KICHARD BARWELL, F.R.C S., CONSULTING SURGEON TO CHARING-CROSS HOSPITAL.

CERTAIN drawbacks and inconveniences are connected with suspension of the patient while applying a plaster-of Istis jacket; of these may be more particularly selected Tainful pressure on the jaw and occiput, as well as on the axillary plexus of nerves. The object of suspension is to straighten out the abnormal curve of the spine, so that the jacket when complete may be straighter than the uasupported back of the erect patient, thus preventing intervertebral pressure, and by successive applications wrocting, as far as possible, the kyphosis or hump which must result if, such means being omitted, the diseased vertebræ synostose. Children, therefore, whose pelves and lower limbs are small and light, obtain little or ane of such benefit; while adults with heavier lower developments may gain more temporary rectification, but cun bear the pressure on the points of suspension a comwensurately shorter time. Hence the plaster must be of such quality as will set quickly; no gum or other colloid worst be combined with it. The jacket must be completed with great rapidity, and not infrequently the patient must betaken down before hardening is so perfect as to obviate eracking and yielding; for, of course, when suspension ceases there is a tendency to recurrence of the curve, which a hastily applied jacket is too weak to resist. Much experience and practice may up to a certain point minimise these evils, but cannot eliminate them.

I have therefore for some years past ceased to employ mapension in kyphosis, and have straightened, as far as safety will permit, the patient's spine by a modification of my method of rachilysis, which, used differently, hos proved successfal in lateral curvature; the force piz., traction by a system of pulleys-being used while the patient is sibting It is thus carried out in a case of dorsal kyphosis : The patient being clothed in a skin-tight knitted vest, and with the usual parts padded, sits on an ordimary office sbool about two feet and a half high, between two opposing walls in which certain hooks \&c. are fixed, 23 for rachilysis. A three inch wide piece of webbing, with strong cords at each end, is secured to one of the back legs of the stool, and, passing over the top of the patient's thisghs sufficiently tightly, is also secured to the other back leg (1). A strip of moderately strong unbleached calico, broad according to the size of the patient, crosses the abdomen on and below the umbilicus. This in the position vender consideration I will name "connter-traction band." By means of the cord at each end it is fixed at the proper degree of tension behind (2). A similar strip of calico passes across the back on a level with the point of greatest Enrve. This is the "traction band" (3). If the projection be very sharp and angular, it is well to make a slit, lengthwise as regards the belt, two or three inches long, so that que of the laps may lie above, the cther below the most prominent vertebra; a cord secured to both ends of this form 3 the whole in to a loop, into which is hitched the hook of the system of pulleys. These two strips of calico would always crumple up and run into ropes as soon as tension comes on them unless prevented, which is easily done by having at hand four slips of common soft wood a little longer than the belts are broad. They are to be placed outside the calico pretty close to the patient's body (4), one on each side, and into them through the belts, and just at their edges, are thrust surveyor's pins (5). Last]y, a one inch wide loop of webbing, properly padded, passes across the manubrium sterni under the axillo on each side, and is secured by a cord running through a single pulley at proper tension behind (6). This I call stmply the "lanyard." Now the surgeon begins by making very slight traction by means of the system of pulleys, observing if the tension of his other cords is correct and places the spine in proper position; if not, it can easily be altered by means of the single pulleys through which the cords run. All being correct, he increases the tension, and slips between the laps of both traction and counter-traction bands a board of wood, from ten to twelve inches long, in order to prevent lateral pressure on the thorax and abdomen (7). He now increases traction up to the desirable point, recollecting that the Astley Cooper system of pulleys, which is that which I use, multiplies his manual force by six. When as much traction as he may deem safe has been attained, he fixes the pulley cord by twisting or knotting it to the loop of the traction belt, thus cansing the spine to be immobile during application of the jacket.

As this sitting position and slight restraint are either not at all or but very little fatiguing to the patient, the next procedures need not be hurried. Moreover, in order to ensure greater hardness and durability to the jacket, some



colloid may advantageously be mixed with the water in which the bandages are soaked. The best and most convenient material I find to be liquid glne (Le Page's). A About a teaspoonful to the $q$ uart of water causes the plaster to set very firm and hard in from twenty minutes to half an hour, according to the warmth of the room. In winding on the bandages those parts of the braction and counter-traction belts which lie close and tight to the patient's body must be included and covered in the turns; those parts which project and stand away from the trunk are left out. By putting on the bandages not straight but somewhat obliquely, the chest and abdomen may be covered, with the exception of some little triangular spaces lying under the shelter-the eaves, if I may use such a term - of the projecting parts; these are afterwards dealt with.

When the plaster has become firm the traction should be slowly relaxed, and the calico belts cut away about three incbes from the trunk, and any little roughness in the angle where they begin to project removed. Then the triangular interspaces should be wetted and covered with plaster soaked in the gluey water. The calico lappets (the three inches not cut away) are then laid over the newly applied plaster and covered by rubbing into them the same material. If the surgeon has to deal with a dorso-lumbar, or with simply a lumbar kyphosis, the lower belt becomes the traction band, passes to the front, and is attached to the pulleys; the upper belt is then the counter-traction band, passing across the front of the chest as high up as one wishes, is secured behind. No lanyard is required.

The advantages of this method over suspension may be thas summed up. 1. Hardly any appreciable fatigne to the patient. 2. No painful pressure on any part. 3. The 
amount of force employed in straightening the spine, instead of depending on such chance condition as the patient's weight, lies entirely within the surgeon's choice. 4 . The surgeon may occupy what time he finds necessary in putting on the bandage, and can make a much more perfected one than when hurried. 5. The admixture of glue renders the jacket very durable and strong, capable of upholding a heavy much-curved trunk. 6. Less plaster is needed, therefore the jacket is lighter. 7. Bits and flakes of plaster do not chip away into the clothing and bed. 8. If a jacket removable by cubting down the middle be desired, a much more springy and less friable one, more easily taken off and put on without cracking, can thus be obtained.

Wimpole-street, $W$.

ON THE

\section{PRESENCE OF URO-H EMATO-PORPHYRIN IN THE URINE IN CHOREA AND ARTICULAR RHEUMATISM.}

BY ARCHD. E. GARROD, M.A., M.D. OxON., F.R.C.P.

Dr. MACMUNN ${ }^{1}$ has shown that a pigment, closely resembling hæmato-porphyrin, to which he has given the name of "uro-hæmato-porphyrin," is meb with in the urine of sufferers from a variety of morbid conditions, and is especially constant and abundant in that of rheumatic patients. This statement has been confirmed by Le Nobel of Leyden, and I have myself found this substance in almost every case of rheumatic fever out of a considerable number in which I have looked for it. I have also found that the pigment present in rheumatic urine usually shows the characteristic five-banded spectrum (described by Dr. MaeMann) in alkaline solution; although I am inclined to thirk that in some of my cases the substance present was ordinary hremato-porphyrin. In acid solution the spectrum of uro-hæmato-porphyrin contains two bands and an intermediate shading, which I cannot distinguish from those of acid hæmato-porphyrin in dilute sulution, and Dr. MeMunn holds that there is also a band like the urobiiin band. The amount present in the urine of rheumatic patients is rarely, if ever, sufficient to impart a characteristic colour to the urine, and, although in some cases the characteristic bands are seen on adding a small quantity of mineral acid to the urine, the presence of this substance can, as a rule, only be recognised by precipitating the pigments and making an acidulated alcuholic extract from the precipitate. Even in such extracts the quantity present is often insufficient to $y$ ield an alkaline spectrum, and when this is the case the recognition of the pigment rests upon the observation and measurement of the characteristic acid bæmato-porphyrin bands. Some recent observations by Salkowski ${ }^{2}$ upon urines containing hæmato-porphyrin render it probable that the adninistration of sulphonal may cause the excrebion of that substance; and it is therefore important to state that the occurrence of uro-hæmato-porphyrin in the urine in acute rheumatism is quite independent of the salicylic treatment; for I have found it in urine passed immediately after admission to hospital by patients who stated that they had as yet had no treatment for their disease, and whose urine gave no salicylate reaction. In the course of a systematic examination of morbid urines for hæmato. porphyrin pigments, I have obtained some results with regard to chorea which I venture to regard as sufficiently interesting to form the subject of a preliminary note. I have examined the urines of twenty patients suffering from chorea, and in fourteen of these bave found uro-hæmato-porphyrin, sometimes in quantities such as are but seldom met with. The quantity of the pigment present appears to bear some relation to the severity of the case; but considerable amounts way be found in the urine of patients who have a persistently subnormal temperature. The analysis of the cases shows that the presence of uro-hæemato-porphyrin is most constant in cases in which there is reason to suspect a rheumatic taint. Of the twenty patients referred to, five had

1 Brit. Med. Journ., vol. ii. 1883, p. 1060 ; vol. ii. 1888, p. 117. Proc. Roy. Soc, No. 208,$1880 ;$ Journal of Phy siology, vol. x., p. 71. definite personal histories of articular rheumatism, and all of these were passing uro-hæmato-porphyrin in their urine-four of them in considerable quantities and one in traces only; two had doubtful histories of articular rheumatism, and both of these had uro-hæmato porphyrin in their urine-one in considerable and the other in unusually large amount. three had murmurs, but nothing else to suggest rheumatism, and of these-two were passing urine containing considerable quantities of uro-hæmato-porphyrin, one with a trace only; two had clear family histories of rheumatism but no personal histories, and no murmurs-the urine of one of these contained a trace of the pigment, that of the other none. The remaining eight patients had no rheumatic family or personal histories, and no cardiac murmurs. Of these, three had uro-homato porphyrin in their urine: one in unusual amount, one in considerable quantity, and one a trace only. The urine of the other five contained no uro bæmato-porphyrin when examined. Since the presence of the pigment in the urine is by no means peculiar to rheumatic cases, but is only an unusually frequent phenomenon in that disease, the above results, did they stand alone, would scarcely offer any evidence of the part which rheumatism plays in the causation of chorea; but, when they are taken in conjunction with the evidence derived from other sources, they must, I think, be acknowledged to supply a fresh link between these two conditions. This conviction gained in force from the fact that I have not obtained such results in other pervous disorders; but up till now my observations on the urine of patients suffering from such diseases are few in number, and it is quite possible that the results of a further search may tend to invalidate this argument. However this may be, I believe that the frequent occurrence of uro-hæmato-porphyrin in the urine of choreic patients affords evidence that one at least of the perverted chemical processes which accompanies rheumatic attacks is shared by chorea; and that it may be ultimately found that the presence or absence of this pigment affords a means more delicate than any which we yet possess of distingnishing which cases of chorea are due to the rheumatic taint and which own some different causation. In conclusion, I must express my thanks to Drs. Sturges, Barlow, Hadden, and Herringham, who have kindly allowed me to examine the urine from some of their cases of chorea.

Chandos-street, $\mathrm{w}$.

ON THE TREATMENT OF

\section{STRICTURE OF THE URETHRA BY HOLT'S METHOD OF DILATATION,}

WITH A MODIFICATION OF VOILLEMIER'S DILATOR.

$$
\text { BY SURgzoN-MAJOR EDWARD LAWRIE. }
$$

For want of an instrument of precision, Holt's method of dilatation of stricture of the urethra has been to a great extent superseded by internal urethrotony. This want has, I believe, been remedied by the introduction of a dilator fulfilling all the requirements of such an instrument, which Messrs. Arnold and Sons have made at my suggestion; and Holt's operation will, I trust, now take its proper position as in all probability the soundesb and safest method of treating organic stricture. The instrument Messrs. Arnold

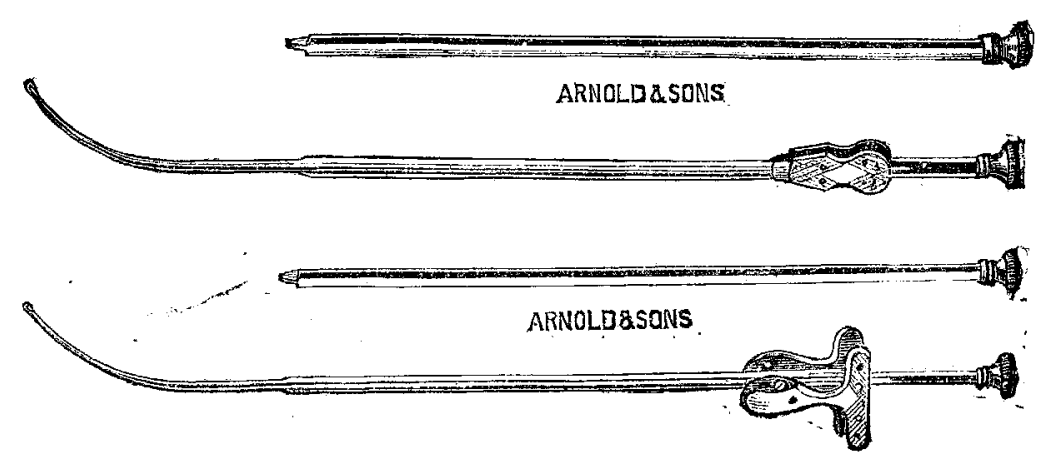

and Sons have made consists of a branching dilator constructed on Voillemier's principle. The branches, which are passed through the constriction as a No. 3 Lister's steel bougie, fit into two grooves in the dilator, so 